\title{
Formation of acyl and alkenyl glycerol derivatives in Clostridium butyri- cum
}

The mechanism of synthesis of plasmalogens is not currently known, but the incorporation of labeled phosphate, acetate, fatty acids, and fatty aldehydes into plasmalogens has been described for intact systems ${ }^{1-6}$. Such isotopic studies have suggested a variety of pathways leading to the synthesis of plasmalogens. Among these proposed pathways are the dehydrogenation of the alkyl ether bond, the reduction of an acyl ester bond, and the dehydration of the hemiacetal formed by the condensation of a fatty aldehyde and glycerol. In the present study, we have observed the incorporation of labeled glycerol into diacyl phosphoglycerides and alkenyl acyl phosphoglycerides of Clostridium butyricum.

C. butyricum (ATCC 60I5) was grown anaerobically at $37^{\circ}$ in a medium, described by WOLFE AND $\mathrm{O}^{\prime} \mathrm{KANE}^{7}$, containing added salts and using alkaline pyrogallol plugs $^{8}$ to maintain anaerobic conditions. Cells were collected by centrifugation during mid to late $\log$ phase, washed with $0.03 \mathrm{M}$ sodium phosphate $(\mathrm{pH} 7.0)$ and resuspended in fresh medium in the presence of labeled glycerol. After incubation at $37^{\circ}$, lipid extracts were prepared as described by GOLDFINE AND BLOCH ${ }^{9}$.

\section{TABLE I}

INCORPORATION OF $\left[2^{3} \mathrm{H}\right]$ GLYCEROL INTO DIFFERENT LIPIDS OF C. butyricum

Cells from I $50 \mathrm{ml} \log$ phase cultures were resuspended in $120 \mathrm{ml}$ of fresh medium in the presence of $50 \mu \mathrm{C}$ of $\left[2{ }^{3} \mathrm{H}\right]$ glycerol $(2.5 \mathrm{C} / \mathrm{mmole})$. Cells were sedimented at indicated times and a total lipid extract was prepared. Aliquots of the total lipid extract were separated on a 0.37 -mm layer of Silicia Gel HR using a solvent system of chloroform-methanol-water $(65: 25: 4$, by vol.). The lipids were visualized by spraying with $1 \% \mathrm{I}_{2}$ in chloroform, and after the $\mathrm{I}_{2}$ was completely removed, the individual bands of the plate were scraped and assayed for radioactivity in $6 \mathrm{ml}$ of scintillation fluid ${ }^{13}$. Recovery of radioactivity was greater than $90 \%$ in all experiments.

\begin{tabular}{|c|c|c|c|c|}
\hline \multirow[t]{2}{*}{ Band* } & \multirow[t]{2}{*}{$R_{F}$} & \multirow[t]{2}{*}{ Idevilily } & \multicolumn{2}{|c|}{$\%$ of ${ }^{3} \mathrm{H}$ incorporated } \\
\hline & & & $90 \mathrm{~min}$ & $180 \mathrm{~min}$ \\
\hline $\mathbf{I}$ & I.O & Solvent front & 3 & 4 \\
\hline 3 & $0.75^{-0.82}$ & Unknown & 16 & 17 \\
\hline 6 & $0.47-0.53$ & Ethanolamine phosphoglycerides** & 30 & $3 I$ \\
\hline 8 & $0.29-0.36$ & Glycerol phosphoglycerides*** & 35 & 33 \\
\hline I I & o & Origin & I & I \\
\hline
\end{tabular}

* No more than $4 \%$ of the counts were in any unreported band, or $15 \%$ in all unreported bands combined.

** Include phosphatidyl ethanolamine and phosphatidyl monomethylethanolamine.

*** Include phosphatidyl glycerol and cardiolipin.

Table I summarizes the incorporation of $\left[2^{2}{ }^{3} \mathrm{H}\right]$ glycerol (Amersham-Searle; $99 \%$ ) into lipids by $C$. butyricum. A partial resolution of the total lipid extract by thin-layer chromatography yielded three major radioactive bands, all three of which gave positive tests for the presence of organic phosphorus ${ }^{10}$ and the alkenyl ether bond ( $\mathrm{r} \% \mathrm{HgCl}_{2}$ in acetic acid followed by Fuchsin ${ }^{11}$ reagent). Glycerol phosphoglycerides (phosphatidyl glycerol and cardiolipin) and ethanolamine phosphoglycerides (phosphatidyl ethanolamine and phosphatidyl monomethylethanolamine) contained about 30 and $35 \%$, respectively, of the incorporated glycerol while a third unidenti- 
fied phosphorus-containing lipid contained about $15 \%$ of the incorporated glycerol. Attempts to demonstrate the presence of isotope in glycerides or fatty acids by thin-layer chromatography showed small quantities (less than $10 \%$ of the total) of isotope in these compounds. Treatment of the lipid extract with sodium methoxide ${ }^{2}$ or with acid followed by alkali revealed that less than $20 \%$ of the label was present in the aliphatic side chains.

\section{TABLE II}

RELATIVE INCORPORATION OF [2- $\left.{ }^{3} \mathrm{H}\right]$ GLVCEROL INTO DIACYL AND ALKENYL ACYL PHOSPHOGEYCERTDES

Nliquots of the total lipid extract were treated with $2 \mathrm{mg}$ phospholipase C (B. ceveus) for I $5 \mathrm{~min}$ in a reaction mixture containing $2.5 \mu$ moles $\mathrm{CaCl}_{2}, \mathrm{I} .0 \mathrm{ml}$ of $0 . \mathrm{I} \mathrm{M}$ Tris-maleate $(\mathrm{pH} 7.4$ ) and $\mathrm{I} .0 \mathrm{ml}$ of diethyl ether. The aqueous layer was twice extracted with $4 \mathrm{ml}$ of ether. After the ether had been removed under nitrogen, the lipid residue was applied to a $0.37-\mathrm{mm}$ layer of Silicia Gel $\mathrm{HR}$, and the plate was developed in a solvent system composed of chloroform-dcetone $(98: 2,5, b y$ vol.). The assay for radioactivity is described in Table $I$ as are the conditions of the incubation.

\begin{tabular}{|c|c|c|c|}
\hline \multirow[t]{2}{*}{ Component } & \multirow[t]{2}{*}{$R_{E}$} & \multicolumn{2}{|c|}{$\%$ of recovered isotope* } \\
\hline & & $90 \mathrm{~min}$ & $\pi 80 \mathrm{~min}$ \\
\hline Alkenyl acyl glycerol & $0.45^{-0.53}$ & 29 & 32 \\
\hline Intermediate band & $0.3^{8-0.44}$ & $x$ & 2 \\
\hline 1,2 -Diacyl glycerols & $0.31-0.37$ & 40 & 36 \\
\hline Origin & 0 & 20 & 26 \\
\hline
\end{tabular}

* The recovery of counts as lipid ranged from 40 to $60 \%$. Chromatography of the products in the solvent system described in Table I revealed that 85 to $95 \%$ of the radioactive phospholipids had been hydrolyzed. Such data suggest that a significant portion of the $\left[{ }^{3} \mathrm{H}\right]$ glycerol was in the nonacylated portion of phosphatidyl glycerol and removed in the aqueous layer as glycerol phosphate.

The incorporation of $\left[{ }^{3}-\mathrm{H}\right]$ glycerol into plasmalogens was estimated by measuring the incorporation of label into alkenyl acyl glycerols and I,2-diacyl glycerols which were prepared from the total lipid mixture by treatment with phospholipase C from Bacillus cereus ${ }^{12}$. Table II shows that $\left[{ }^{3} \mathrm{H}\right]$ glycerol was present in both the alkenyl acyl glycerols and diacyl glycerols with the diacyl fragments containing more isotope. Variations, however, were observed in the ratio of isotopes for the diacyl glycerols to alkenyl acyl glycerols from experiment to experiment.

The experiments summarized in Table II show that $C$. butyricum incorporated exogenous $\left[{ }^{3} \mathrm{H}\right]$ glycerol into both diacyl and alkenyl acyl phospholipids, but the pathway by which the glycerol was incorporated into plasmalogens is not apparent. Recent studies of SNYDER et al. ${ }^{14,15}$ demonstrated that synthesis of the alkyl ether bond can occur via the condensation of glyceraldehyde 3-phosphate and long-chain alcohols with subsequent formation of a I-alkyl-2-keto derivative. An alkyl glycerol produced by such a pathway could serve as precursor for the alkenyl glycerols in a manner described by THOMPSON ${ }^{16}$. The possibility that such a mechanism might be operative for the synthesis of plasmalogens in $C$. butyricum was tested by estimating the incorporation of a mixture of $\left[2^{-3} \mathrm{H}\right]$ glycerol and $\left[{ }^{14} \mathrm{C}\right]$ glycerol (International Chemical and Nuclear Corp.; $99 \%$ ) into lipids of C. butyricum. If the synthesis of the vinyl ether bond occurs via the mechanism outlined above, the ratio of ${ }^{3} \mathrm{H} /{ }^{14} \mathrm{C}$ in plasmalogens would be essentially zero since the ${ }^{3} \mathrm{H}$ at Position 2 of glycerol would be labilized during formation of the keto derivative.

Table III shows the ratio of ${ }^{3} \mathrm{H} /{ }^{14} \mathrm{C}$ in the total lipids, glycerol phosphatides, ethanolamine phosphatides and the 1,2-diacyl glycerols and alkenyl acyl glycerols 
TABLE III

INCORPORATION OF [2- $\left.{ }^{3} \mathrm{H}\right]$ GLYCEROL AND $\left[{ }^{14} \mathrm{C}_{3}\right]$ GLYCEROL INTO LIPIDS BY C. butyricum The experiments were as described in Tables I and II. Results are expressed as the ratio of ${ }^{3} \mathrm{H}$ to ${ }^{14} \mathrm{C}$. The initial substrate had a ${ }^{3} \mathrm{H} /{ }^{14} \mathrm{C}$ ratio of $\mathbf{1} \cdot 32$.

\begin{tabular}{llllll}
\hline $\begin{array}{l}\text { Expt. } \\
\text { No. }\end{array}$ & Total lipid & $\begin{array}{l}\text { Ethanolamine } \\
\text { phosphoglyceride }\end{array}$ & $\begin{array}{l}\text { Glycerol } \\
\text { phosphoglyceride }\end{array}$ & $\begin{array}{l}\text { Diacyl } \\
\text { glycerols }\end{array}$ & $\begin{array}{l}\text { Alkenyl } \\
\text { acyl glycerols }\end{array}$ \\
\hline I & 6.74 & - & - & 4.61 & 6.46 \\
2 & 5.87 & - & - & 5.56 & 4.95 \\
3 & 2.42 & 2.19 & 3.14 & - & - \\
7 & 4.02 & 3.92 & 5.16 & 4.03 & 4.09 \\
8 & 5.08 & 5.76 & 3.92 & 4.53 & 5.26 \\
\hline
\end{tabular}

derived from the total lipid extract. The ratio of ${ }^{3} \mathrm{H} /{ }^{14} \mathrm{C}$ in the total lipids exhibited considerable variance $(2-6)$, but the ratio was always greater than that of the glycerol (I.32) supplied to the bacteria. The ratio of ${ }^{3} \mathrm{H} /{ }^{14} \mathrm{C}$ in the glycerol or ethanolamine phospholipids was similar to the ratio observed in the total lipid extract. Likewise, the ${ }^{3} \mathrm{H} /{ }^{14} \mathrm{C}$ ratio of diacyl glycerols and alkenyl acyl glycerol was similar to that of the total lipid extract.

Our results indicate that the hydrogen at Position 2 of glycerol was not labilized during the incorporation of glycerol into plasmalogens. Such a finding precludes the possibility of the pathway described by Snyder serving in the formation of alkenyl derivatives in $C$. butyricum. In addition, the pathway described by HAJRA ${ }^{17}$ does not seem involved in converting the glycerol to lipid. The similar ${ }^{3} \mathrm{H} /{ }^{14} \mathrm{C}$ ratios for the diacyl glycerol and alkenyl acyl glycerol units of different classes of phospholipids suggest that a common pool of glyccrol, enriched in $\left[2{ }^{3} \mathrm{H}\right]$ glyccrol, served as the precursor of both types of phosphoglycerides in this organism.

This work was supported in part by a grant (AM 053Io) from the Uuited States Public Health Service.

Department of Biological Chemistry,

EDWARD E. HILL* The University of Michigan, Ann Arbor, Mich. 48 Io4 (U.S.A.) William E. M. Lands

i N. A. Bauman, P.-O. Hagen and H. Goldfine, J. Biol. Chem., 240 (1965) i 559.

2 J. Ellingboe and M. Karnousky, J. Bivl. Chem., 242 (I967) 5693.

3 P.-O. Hagen and H. Goldfine, J. Biol. Chem., 242 (I967) 5700.

4 R. Bickerstaffe and J. F. MEAD, Biochemistry, 6 (1967) 655 .

5 G. A. Thompson, Jr., Biochemistry, 5 (I966) I 290.

6 O. E. Bell, Jr., ANd H. B. White, Jr., Biochim. Biophys. Acta, I64 (Ig68) $44 \mathrm{I}$.

7 R. S. Wolfe and D. J. O'Kane, J. Biol. Chem., 205 (I953) 755.

8 J. K. Hardman and T. C. Stadtman, J. Bacteriol., 79 (I960) 544.

9 H. Goldfine and K. Bloch, J. Biol. Chem., 236 (I96I) 2596.

lo J. C. Dittmer and R. L. Lester, J. Lipid Res., 5 (1964) 126.

I I H. R. WARner and W. E. M. LANDS, J. Lipid Res., 4 (I963) 2 I6.

I 2 E. E. Hill, D. R. Husbands and W. E. M. Lands, J. Biol. Chem., 243 (Ig68) 444 o.

I 3 F. SNYDER, Anal. Biochem., 9 (I964) I 83.

I 4 F. Snyder, B. Malone and R. L. Wykle, Biochem. Biophys. Res, Commun, 34 (I969) 40.

I5 F. SNyder, R. L. Wykle and B. Malone, Biochem. Biophys. Res., Commun., 34 (1969) 315.

16 G. A. Thompson, Jr., Biochim. Biophys. Acta, I52 (1968) 409.

I7 A. K. IIAJRa, J. Biol. Chem., 243 (1968) 3458.

Received September 22nd, I969

* Present address: Department of Biochemistry, University of West Virginia, Morgantown, W. Va., U.S.A. 